\title{
A Differentiation of Gifted and Talented Singers
}

\author{
Mohd Azharabu Bakar @ Azmeer ${ }^{1}$, AdzroolIdzwan Ismail ${ }^{2 *}$, Ahmad Hisham Zainal Abidin ${ }^{3}$ \\ ${ }^{1}$ University Fellow, School of Creative Industry Management \& Performing Arts,Universiti Utara Malaysia \\ ${ }^{2,3}$ School of Creative Industry Management \& Performing Arts,Universiti Utara Malaysia \\ ab.azmeer@yahoo.com¹, adzrool@uum.edu.my ${ }^{2 *}$,hishamza@uum.edu.my ${ }^{3}$
}

Article History: Received: 10 November 2020; Revised: 12 January 2021; Accepted: 27 January 2021; Published online: 05 April 2021

\begin{abstract}
This journal purposes on the studies of correct vocal singing techniques and knowledge sharing information. The methodology used in this study was throughacquiring vocal aesthetics and improvisations in singing skills from gifted singers derived through interviewsfromsome of Malaysia's mostgifted stars. The discovery of this study with regards to theanalysis on the differentiation of vocal characteristic aims to indicate positive and innovative results against negative and stereotype emulated singing of amateur singers. Through the findings of this research, amateur and aspiring new singers shall be able to learn to sing and perform properly. The main findings and results aretabled from the top to the least based on important tips like feel, innovative methods, techniques and creativity invarious singing performances. Practical contribution of this study will be a useful guideline not only to artistes but vocal teachers and record companies.
\end{abstract}

Keywords:vocal aesthetics, improvisations,vocal characteristic,emulated singing, innovative methods, techniques and creativity.

\section{Introduction}

The aim of this study is provide new singers guide to understanding structured vocal training framework based on the tips and guidefromgifted singers. These guidelines are the main aspects that is looked into due to the credibility of information source. Knowledge transfer play important roles in steering proper direction towards contributing to the improvement and development of singing standards in Malaysian. This approach customized in deriving knowledge fromthe maestros is useful and beneficial for developing new singers' full potential.

This is supported by what is written by writers MarienneUszler, Stewart Gordon, Scott McBride Smith (1991) in "The Well-Tempered Keyboard Teacher". Uszler said a 'gifted' person acquire that gift since birth or congenital, whilst the 'talented' are a group who are trained to be good. Evidently the 'gifted' singers are mostly better than 'talented' group. Proper singing techniques should be conveyed to home grown budding talents through knowledge transfer. Based on Marienne's theory, various aspects of singing knowledge shall be identified from gifted singers in Malaysia. These knowledge and information derived shall be channeled to upcoming singing talents for the benefit of amateur and aspiring new singers in the Malaysian music industry.

To achieve a relevant information guide for singers, knowledge on singing tips were shared by gifted respondents based on questions related tosinging starting age,family influence and support, exercise and nutrients, sincerity, feel and appreciation, creativity, multiple intelligence and music theory awareness.

\section{Literature Review}

This study focuses on multiple disciplines for singers to have a holistic understanding on proper singing methods. The basic concepts of singing can be narrowed down to the very basics of vocalization to the extravagant aesthetics of singing embellishments.

We know that men began to sing long before they were able to speak. This does not necessarily mean singing in on stage. Speech originated from singing simply means that our comparatively monotonous spoken language are similar to primitive utterances like the singing of birds, the roaring of animals and the crooning of babies. They then evolve into our highly developed vocal music.

"The oldest, truest, most beautiful organ of music, the origin to which alone our music owes its being, is the human voice." - Richard Wagner\& Rackham - The Ring of the Nibelung.

Otto Jespersen. Language, Its Nature, Development and Origin. (1922), wrote on the relevance of sound along with minimum visuals in portraying a National Park. Sound plays a vital role in enhancing sensation and emotions to human being. This neuro-design symbiosis naturally reciprocate resulting in pleasure and sensation to human senses 
"Our remote ancestors had not the slightest notion that communication ideas and feelings were possible."Otto Jespersen, Language, Its Nature, Development and Origin. (1922)

Singing is thetranslational tool of telling thestorywithin the song delivered by the human vocal throughexpression and eclectic movementsof musical notations. This is supported by the statement below.

“A relationship with the context of the created lyrics is viewed as how life themes are applied." (Logan 2004 Parveen, (2017).

Fundamentals of music theories should be introduced to singers using the simplest approach possible.As an industrialist, the writer would like to introducethree basic fundamentals of musical notes movements: vertical movement, horizontal movement and accents ${ }^{i}$ of music- (VHA) ${ }^{\mathrm{ii}}$.

Vertical movement are the intervals ${ }^{\mathrm{iii}}$ of thelinear melodies; whereas the horizontal movement are the note values or length - rhythmic beats. The accent is the velocity and dynamics induced into the singing/melodyembellish feel and expressions. Singing uses the most vital tool which isthe human voice. The word of "vocal" originated from the Latin word "vok" or "vox" meaning "voice" firstused in the 15th Century (1582). It is related to the word "vocare" which means "to call".

"Good sound is beautiful and mesmerizing."... "In the beginning was the voice. Voice is sounding breathe, the audible sign of life." -John Coopman (1999) mention of prehistoric vocalism.

The relationship between communications in sound is relatively connected to visual. This above quote by Coopman would be relevant to what is mentioned in a journal by FritsHesselink, the Chairman of the IUCN Commission for Education and Communication 'Communicating nature conservations 10 frequently made mistake', visual is one of the media of communication.

'I feel that very often nature conservationists do not define their problem properly. For example quite often when designating a new national park they communicate by producing poster or leaflets as means of communicating the message on how important the park is. This is in fact nothing more than pure propaganda. And in most cases it is not very useful'.

- FritsHesselink

Like visual, singing is also a medium of communication. Effectiveness of visual alone is however questionable. Deliverables of engagement probabilities to the audience or observer may be disputed.

Famous Malaysian singer Yunaexpressed this symbiosis of music and visual in her following statement:

“...people can just listen to the song and enjoy the beauty. It's a moving photograph in the end. I just wanted to do something different where the fans can enjoy the cool visuals with their listening experience" - Yuna

https:/www.Intvglobal.com/id/article/how-malaysian-singer-yuna-became-rbs-brightest-new-star/

Vocal is a medium or tool of communication. According to Hanspeter, H. (2011) vocals have impacted the industry inmany different ways. Business organizations for example,operate by call centers through thehuman voice.

Besides citation references, local reviews through articles, books and write - ups shall help substantiate this study. Support statements from prolific composers and producers shall be inserted. Collectively, all the literature reviews shall corroborate what all of the respondents' statements.

Keywords: vocal aesthetics, innovative methods, vox, vocare,neuro-design,accents, maestros, primitive utterances.

\section{Basic Knowledge on Music}

A song comprises of the melody, lyrics, and musical arrangement. The melody is normally sung by the singer unless it is instrumental. The process of making the melody is done by the composer; the lyrics written by the lyricist;and the producer manages the whole processof recording the album or a single.The music arranger organizes the musicians and reports to the producer. 


\section{The Human Voice}

Like a violin, viola or cello, the human vocal cord ${ }^{\mathrm{iv}}$ is fretless. It is unlike the guitar which has frets and the keyboard of the piano which has keys making it possible for the human vocal to do vocal variations like slur ${ }^{\mathrm{v}}$, glide, vibrate, syncopate ${ }^{\mathrm{vi}}$, accents and dynamics in singing.

A good performance must be majestic. With the acquisition of basic knowledge, a singer may be able to execute tasks of performing easier. These knowledge may eliminate the element of stage fright that may cause discrepancies in a performance. We shall now visit the basic approach to making a singing performancemagnificent.

Approach of information on basic music must be made simple so as to induce the easy pedagogical comprehension for music theory beginners. Knowing the method of viewing music instead of just listening to it helps singers place their intonations correctly.

The famous five stave of the music lines explained by looking at the five human fingers on the hand is good information for beginners. For the treblestaff ${ }^{\text {vii }}$ notes positioning, an imaginary pen below the thumb represents the middle $\mathrm{C}$ and each finger from the lower to upper represents the notes E, G, B, D and F respectively. Spaces between fingers from the lowerto upper are the notes F, A, C, E respectively. The bass staff ${ }^{\text {viii }}$ can be represented by fingers of the fingers of the other hand below the middle $\mathrm{C}$ (imaginary pen) - G, B, D, F, A from lower to upper respectively. Spaces between the fingers are A, C, E, G from lower to upper.

The "currency"metaphorfor basic music may be interpreted as:

- One crochet $=\$ 1$,

- One minim $=\$ 2$,

- One dotted minim $=\$ 3$,

- One semibreve $=\$ 4$

- Quaver $=0.50$ cents,

- Semi quaver $=0.25$ cents.

- Rests can be translated as stolen money.

Keywords:Treble staff, bass staff, keys, intonations, fretless, eclectic movements, slur, glide, vibrate, syncopate, accents, dynamics, eclectic, "vox", vocare,currency metaphor.

\section{The Fundamentals of Singing}

After knowing the above metaphoric denominations, singers then must familiarize themselves with the next stage of fundamentalsinging factors to contribute greater radiance. Gifted singers do not relinquish fundamentals. They are equipped with the knowledge of understandingthe total composition of art. These behaviorare neurodesigns of the brain is supported by the following:

"New findings about the role of neurotransmitters, neural networks and brain systems are coming out regularly, ushering in a new era of understanding of how we think."- John Daniel Scott

In his article, John Scott mentioned that Daniel Levitin had written the books 'This Is Your Brain OnMusic' and 'The World In Six Songs'. Levitin was as a music producer, producing multiple gold records before becoming a Professor of Neurochemistry at McGill University. His very informative insights into the effects of singing on the brain shows that people who sing are more likely to be happy is line with observations made by Levitin on his vocal students.

Besides the brain, the physical human body is important in singing. Diet and exercises help keep the body fit. An article supporting this is as follows:

"Body Weight, Nutrient, and the Classical Singer: A Review of the Existing Literature"

2017-04-21 - Rebekah Kaye Smeltzer, University of Miami;

Rebekah compared singers to "vocal athletes".

"Thus, it is good for them to have a healthy and balanced diet." 
"Food must be chewed thoroughly, otherwise there is risk of regurgitation (the action of bringing swallowed food up again to the mouth)".

"Obesity restricts the motion of the diaphragm, interferes with lung expansion."

"Physical health and vocal health have a symbiotic relationship, and current research indicates that obesity, which contributes to health concerns such as cardiovascular disease and type II diabetes, has no provable benefit to a singer." - Rebekah Kaye Smeltzer

"No one body weight or type is the most appropriate or "best" for operatic singing. Throughout the history of the art form, singers of all physiques have had successful careers. However, the evidence demonstrates that singing is most efficient when the singer is at a healthy body weight. A singer's instrument is their body, and all body functions are more efficient at a healthy weight."

\section{- Rebekah Kaye Smeltzer}

Exercise and diet are essential practices that singers must abide. In order to sustain a whole song let alone a concert, fitness cannot be taken lightly.

There are several basic fundamentals of singing that gifted singers possess and all singers should know. These points are important before a singer can comprehend the other factors contributing to performance excellence.

- Key- The "key" introduces the song to the singer. It can also be construed as the 'introduction' of a song,giving the singer the key of the song. If a singer is unable to identify the key, then he'll sing "off-key".

- Intonation - Intonation or pitching is very important in singing. The music supports the singerto sing the in right key throughout the song. The placement of every single note of the melodyblending into the music throughout the song determines perfect intonation.

- Breathing space-In order to sing correctly, one is not allowedto breathe in between a phrase. Breathing at wrong places dampen and distort the articulation and expressions aesthetics of flow. Breathing is best taken after a complete phrase. This is interrelated to proper phrasing.

- Proper Phrasing - unnecessarily suspending or halting a phrase is singing is a serious mistake. A sentence like "The wandering mind is..." will sound wrong if it is sung as "The one...(singing halts)...the ring my knees".

- Articulation - Pronunciation and diction must not be taken lightly by singers. Improper pronunciation doesn't convey the story. Listeners must be able to understand what the singer is trying to share.

- Warm up-All sports need warming up. Simple sit-ups or abs crunches may help. Slowly rotating the neck in both directions stretch neck muscles. Simple wall push-ups mayhelp a singer to warm up before appearing on stage.

- Extroversion -Excessive talking taxes the throat and vocal cord. Gifted singers would remain calm and collected without talking too much before singing. This enables the singer to prepare physically and mentally the story he is about to deliver.

- Knowing your audience - It is best for a singer to know the audience before giving a performance. If a singer knows his audience he can ensure smooth renditions. If there areV.V.I.Ps present, the singer should know the proper protocols and salutations and perform well without uncertainties.

\section{Differentiation of Gifted and Talented}

In the book "The Well-Tempered Keyboard Teacher" 2nd Edition, MarienneUszler, Steward Gordon and Scott McBride-Smith wrote that gifted is congenital or in-born and the talented are those who are trained to become excellent.It is also believed by many that superstars are gifted artistes. 
A composer and producer on the other handare the key persons in making the song and music respectively. Songs are like roots to a tree. Composers produce "custom-made" songs suiting the vocal range of a particular singer. The healthier it is the more beautiful the tree becomes.

\section{Multi disciplines}

It is important for a singer tohave multi-disciplinary skills. Gifted singers tend to have greater dexterity and flamboyance in performances. They require lesser tasks in achieving great success compared to mediocre groups.

Keywords:Vocal athletes, intonation, articulation, expressions, diction, extrovert, custom-made, multidisciplinary.

\section{Emulations}

The abundance of sub - standard mediocre singers who imitate the styles and tones of their gifted idols results in unsuccessful and unsustainable singing career. Most of them turn to acting and hosting television shows. This generally shows that singers without tone originality cannot survive the competitiveness music industry.

On the contrary, gifted singers get recording contracts and become successful because of tone originality. Those who are gifted, or even the very talented ones record albums because they congenitally have unique voice tone or 'signature tone'. Those who emulate the style and tone of their idolsare certainly not sustainable. Whitney Houston and Christina Aguilera however is an exception. They may have similar vocal acrobat techniques but their vocal timbre, tone and resonance are rather different.

\section{Malaysian Music Scene}

The local music industry is commendable. Several Malaysian artistes achieved international success with their repertoires. The late Sudirman and current divas like Dato'Sri Siti Nurhaliza, ShilaAmzahand Yuna made their marks internationally. Besides them, othergifted singers in Malaysiaare Dato' Jamal Abdillah,Dato'M. Nasir,Misha Omarand Dato' Sheila Majid. These are examples of gifted singers with 'signature tones'. Signature tones ${ }^{\mathrm{ix}}$ are voice-tones that are recognizable just by listening to their singing.

\section{Methodology}

The method of this study include interviews, literature studies and findings analysis. With qualitative design elements, this study shall be based on interviews conducted through gifted singers involving vocal characteristics studies. This would enable writers to dissect and analyze cognitive skills and psychoanalysis ${ }^{\mathrm{x}}$ understanding of the gifted towards the art of singing.

The rule of thumb in singingis to sing in tune. Practicing ear training develops the correlation of parallel responses between brain and in-tune vocalization. Behavior and neural design of the brain in adhering required tunes is natural amongst the gifted singers. They most probably are congenitally bornwith it while many others require lots of practice.

This study also focuses on identifying and analyzing the attribution theory of gifted singers, progress, developments. Results pertaining to vocal capabilities of the gifted in relation to movements of melodic notations discipline, creative vocal composition discipline, and tone quality discipline shall be discussed. Likewise, results on creative natural delivery through multiple intelligence eliminating emulation shall be documented.

Understanding the strategies and methods applied bythe gifted in achieving perfect intonation or "perfectpitch", tone, color, natural dynamics in perfect rhythm, tempo and style is important. Virtuoso singing encompasses the cohesive efforts ofneumatic - simple (two to five notes per syllable) to highly the melismatic ${ }^{\mathrm{xi}}$.

Natural skills; kinesthetic intelligence and multi-turns vocal embellishments, excellent song texts, distinct articulation and aesthetic linguistics are great elements in singing. They would certainly propel and propagate a collective composition of grandeur vocal renditions with a spectacle of visual magic.Collaboration of these elements integrated with cognitive and also the creative non-cognitive skillsof exploring the difficult application of multiple intelligence pertaining to the research questions will certainly be beneficial to new singers in obtaining higher singing standards. This research can be adapted and refined to suit the aesthetics, creative expressions and musical appreciation. 


\section{Selected Respondents}

Gifted respondents will be selected based on their track record and success in order to achieve the objectives of this study. Reasons for the selections are because of the undeniable knowledge they acquired through experience based on their respective outstanding career achievements. This is relevant as it is mentioned by Hans-Peter Blossfeld and Jutta Von Maurice that education is a lifelong process.

\section{ZeitschriftfürErziehungswissenschaft 14 (2), 19-34, 2011. link.springer.com}

"Education in modern societies has become a lifelong process. That is why the principles of life-course research, as stated by Glen H. Elder, are of utmost significance in empirical education research: (1) focusing on long-term educational processes over the individual lifespan; (2) considering individual educational pathways within their institutional and social embeddedness (e.g., within not only formal educational institutions but also non-formal/informal contexts such as the family, peer groups, and other social networks)."- Hans-Peter Blossfeld, Jutta Von Maurice

The total respondents selected are twotop Malaysian artistesand one Indonesian artiste who are successful in their career achieving multiple awards. This journal however focuses only on three most senior stars as they command a longer span of success track records. The three selected legendary artistes are coded as:

G1 Dato' Jamal Abdillah,

G3 Dato' M. Nasir, from Malaysia and

G6Hetty KoesEndangfrom Indonesia who is also a successful megastar in Malaysia.

\section{Aims of Study}

This study aims to provide new singers guide to understanding structured vocal training framework based on the following:

- Investigating the "sustainable" factor in the gifted singers" career path, multiple intelligence and knowledge in singing.

- Investigating their abilities in maintaining good singing voice and the synergy of trans-disciplinary between the vocal and the music accompaniment.

\section{Objectives of Study}

The objectives of this study are to identify:

- The starting age of the gifted singers and persons who influenceand supported them.

- To identify the various approaches, criteria and factors of spectacular singing.

\section{Interview Questions}

The interview questions will be based on the aims and objectives of this study. Questions cover the aspects of very early starting age, close family influence on singing career, professional sustainability factors and the spectacular magical factors in attaining a majestic and magnificent performance.

Results from this study may help encourage progress and generate reciprocal responses from both singers and listeners through the spectacle of sound and visual through proper singing techniques and methods.

Keywords:Emulation, signature tone, vocal acrobat, cognitive skills, psychoanalysis, creative vocal composition, neumatic, melismatic, sustainable, majestic magnificent, spectacle of sound and visual. 


\section{Results and Discussion}

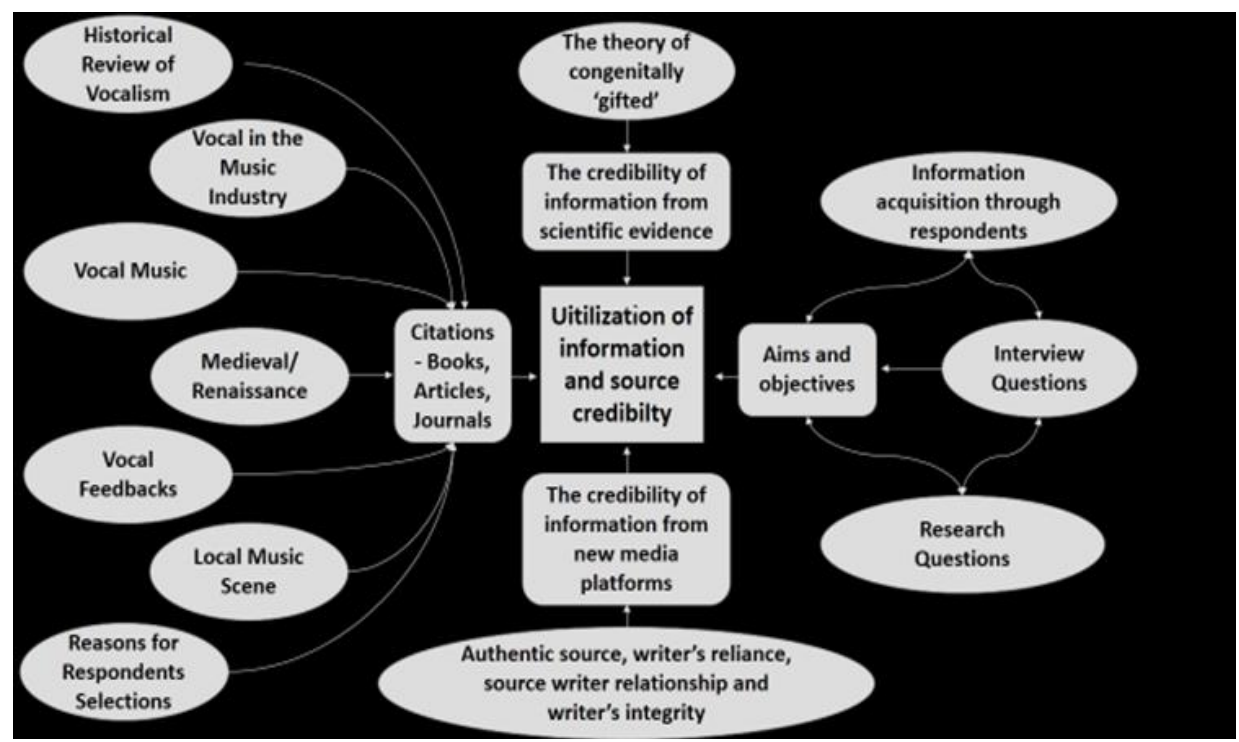

Figure 1. Conceptual Idea

Figure 1 shows the conceptual idea of this study. Citations of historical reviews, vocal music in the local music scenewere derived from books, articles and journals. Information from respondents derived from the interview questions relate to the aims of this study. Scientific evidence shall corroborate the theory of congenitally gifted and the writer's source authenticity, relationship and integrity bring about the credibility of new media platform of information. All of these contribute collective information guide and tools for aspiring new singers in Malaysia.

To attain a spectacular performance, respondents prioritized early start;family influence, exercising; and to have sincerity, feel and appreciation. The results derived from the interviews show diversity in views relating to the first question on young beginner and influential persons. Only one senior respondent answered touched on this question.

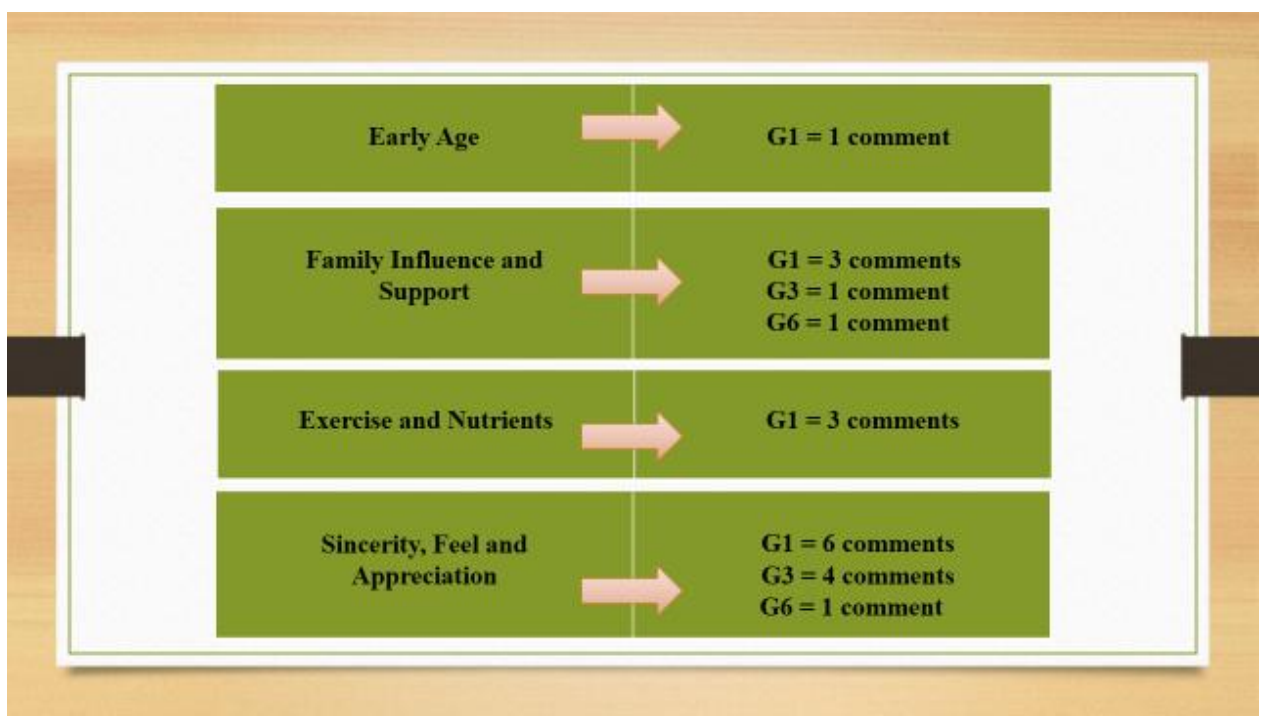

Figure 2.Results 1

a)Early Age

Figure 2 shows only one respondent answered the question pertaining to starting at early age.

$$
\text { G1 = } 1 \text { comment }
$$




\section{b) Family Influence and Support}

All three respondents said that they were influenced and supported by very close family members.

G1's father played the crucial role in terms of contribution and guidance. His mother inspired him.

G3's eldest brother gave a lot of influence supported the passion for music. Besides inheriting singing talent from both father and mother, G6's whole family loves singing.

\section{G1 $=3$ commentsG3 $=1$ commentG6 $=1$ comment}

\section{c) Exercise and Nutrients}

Health and stamina are also important for note placements in singing. Inadequate breath would not help a singer to hit certain notes. Only G1 emphasized the essentiality of exercise and nutrients. G1 said that only a fit body can have energy to project the voice. G1 also said that exercise makes you look younger and holding breath under water helps improve breathing.

G1 reminds new singers to take care of eating habits. Adaptation of hot, spicy food or drinking ice water is individualistic.

Although only G1 commented on this, it does not mean that the other respondents do not agree on the importance of exercising and eating habits. They may have just believed that it is needless to reiterate these element of exercise isbasic in acquiring good health and stamina in singing.

\section{G1 = 3 comments}

d) Sincerity, Feel and Appreciation

G1 sincerely believes in the gift from God. Feeling the song and burying it in the heart is sublime.

One must take that feel in order to get the feeling. Focusing on factors that may arouse the feel in you is also important for G1.

G3 suggests that skills and mastery in technique, tone and outlook is relatively close to an acting performance. Not all songs have to dramatic. Natural elements may produce spectacular elements.

Proper placements in the artistry of vocal acrobatics can derive the feeling sensation.G3 also said art is the feeling that demands honesty and not hypocrisy.

G6 simply asks singers to do it from the heart and never treat it as a burden.

Sincerity is utmost important in singing. The concept of understanding of the "story" in the lyrics is evident amongst most of the gifted singers. If the message is not delivered, aesthetics of the song is jeopardized and diminished.

All the three respondents commented on this. G1 gave the most points when commenting on the importance of being sincere, having absolute feeling and appreciation in fulfilling the task of singing. G3 gave four comments and G6 one.

$$
\text { G1 }=6 \text { comments } \quad \text { G3 }=4 \text { comments } \quad \text { G6 }=1 \text { comment }
$$

e) Secret of Success

One of the factors in achieving sustainability is to gather the secret formulas through proven success. All the three respondents revealed their secrets pertaining to this question. 


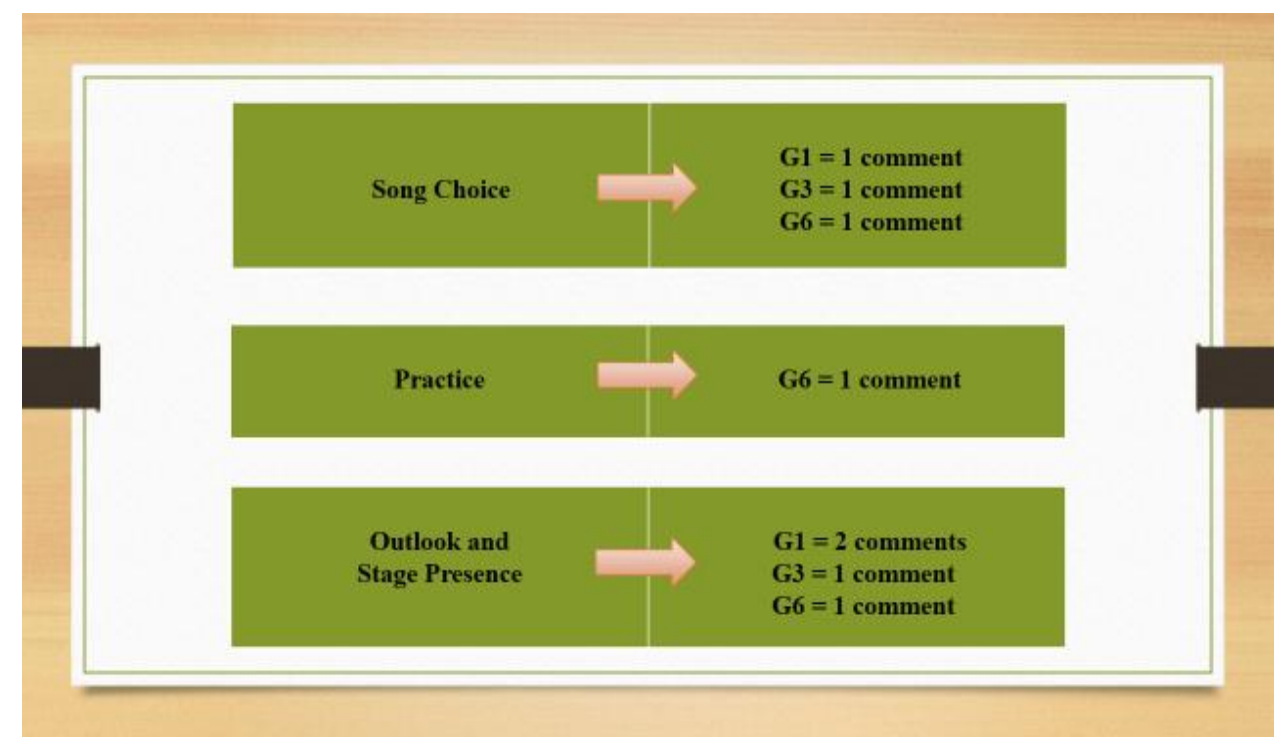

Figure 3.Results 2

\section{f) Song Choice}

In order to sustain, a singer must be able to identify a hit song when listening to one. Again all three respondents believe on the importance of this factor. Working closely with composers and heeding to their advice is recommended.

"In this generation, a singer gets what he wants. But those days, they had to slog to create a song. The recording then was what the singer actually sang without the assistance of gadget systems to enhance the vocal quality." - Ahmad Nawab-'BakalSenasibP.Ramlee'

- Utusan Online 1-9-2015

In Figure 3. G1gave one comment on song choice. G1 said that working closely with the composer to choose the right song is important and emphasized that an artiste must have the will to be in the industry forever.

G3 said that in order to be regarded as a great singer, one must have more than ten hit singles in hand and to become an evergreen singer, the singer cannot fabricate.

G6 mentioned that a singer must keep abreast with the latest trend of songs and strongly recommends consistency in the quality of work.

\section{G1 = 1 comment $\quad$ G3 $=1$ comment $\quad$ G6 $=1$ comment}

\section{g) Practice}

Practice makes perfect. Another factor in order to have a sustainable singing career is to have much practice. G6 stressed out that a singer must "practice, practice, practice and have enough rest".

\section{G6 $=1$ comment}

h) Outlook and Stage Presence

Relating to expression in a performance, author Meribeth Bunch Dayme in chapter 7 of her book "The Singing Book, Dynamics of the Singing Voice, and Creating Confidence"- published in 2000, wrote;

"The ability to express yourself freely on stage is the key to excellent communication with your audience. The audience knows when a performance is convincing".

"Inexperienced performers often compensate by being over the top with energy or by being too casual."... "This amounts to cheating the audience" - Meribeth Bunch Dayme 
Another factor related to career sustainability is to have good outlook and stage presence. All of the three respondents see the need to this factor. A performance may turn stale if it is carried out haphazardly. Both the artiste's appearance and the stage preparations must be taken seriously.

G1 pointed out that the outfit must be comfortable in order to get maximum vocal output and stay looking young. G3 relates the symbiosis of singing with acting and not overdoing them. G6 looks at various aspects including make - up and accepting views from others on outlook.

\section{G1 $=2$ comments G3 $=1$ comment $\quad$ G6 $=1$ comment}

i)Multiple Intelligence

The last question involving multiple intelligence comprises of two sub elements of creativity and music theory awareness amongst singers.

Multiple intelligence may be enhanced or obtained through music theories. A singer may be able to know the proper procedure in executing a singing performance by understanding music.

G1 strongly trusts that creativity cannot be dispensed with when it comes to singing and performance. G1 said that a singer must eliminate feeling nervous by analyzing factors that may contribute to it. A singer must have intelligent quotient. G1 also advise singers to be aware of surrounding factors on stage.

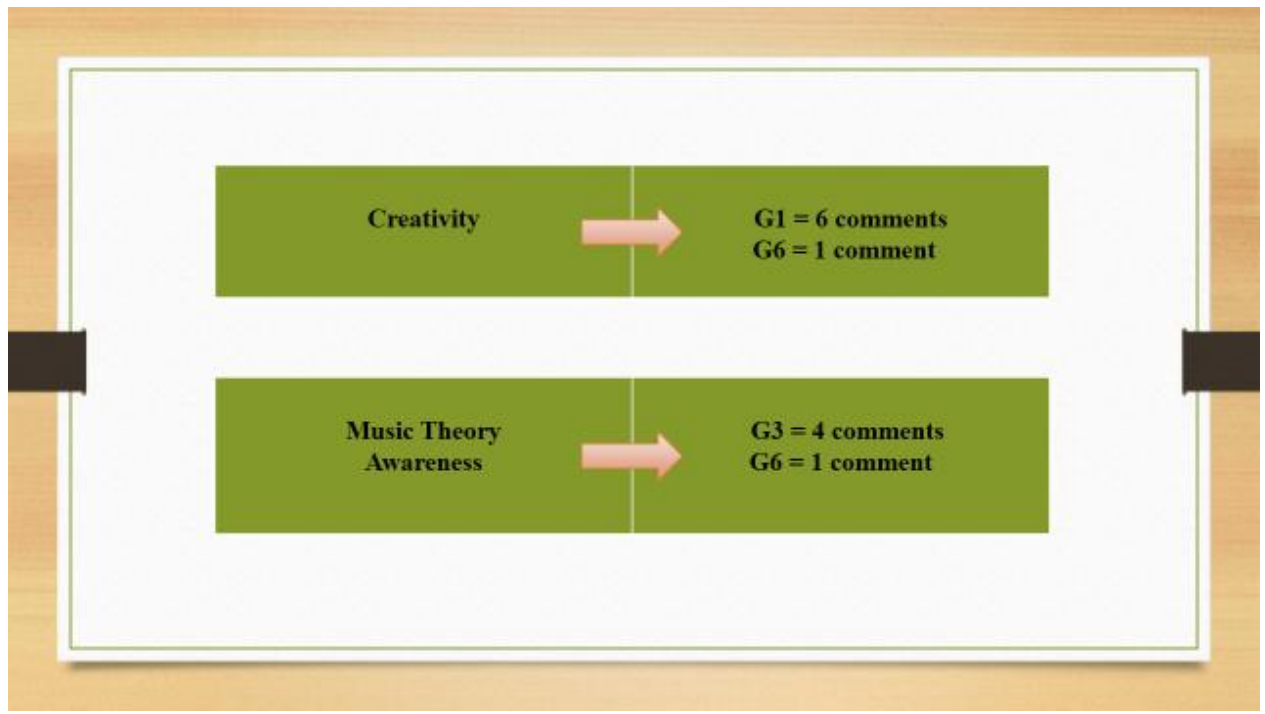

Figure 4.Results 3

\section{j) Creativity}

Creativity involves the understanding of the important functions of music accompaniment. Music helps control the pitch of the singer.

In Figure 4,G1 gave six comments and creatively utilizes music as his tool for intonation or pitching. He mentioned that the 'bass' is the root of the music and it is very important for the singer to pay attention to it when singing. He added that a singer must conserve energy before going on stage by focusing and not talk unnecessarily as it may be taxing to the vocal cord. bad.

G6 commented referring to various references to gather ideas and enhance only from the best not discard the

One must possess the ability to express creativity freely on stage. It is a convincing factor in order to achieve excellent communication with the audience when doing a performance. Thisis supported by what is written by Professor Tan SooiBeng and Patricia Matusky in 'The Music of Malaysia: The Folk and Syncretic Traditions'.p.35

"Malaysian traditional music like Mak Yong, is also performed by giving freedom to the performers to improvise." 
Referring to a book entitled 'Composing For Voice - Exploring Voice, Language and Music' by Paul Barker and Maria Huesca. The authors wrote the fact:

"Without the full technical support poet and composer, singers have to work harder, look deeper into their own creativity. ” p 47 - Paul Barker and Maria Huesca.

\section{$R 1=6$ comments $\quad$ G6 $=1$ comment}

k) Music Theory Awareness

"The Hebrew Torah, the Greek myths, the Iliad and the Odyssey, were all sung long before they were first written down. So when we sing, we tap into something that is not only one of the most ancient of human practices, but we also tap into the activity that modern neurochemistry ${ }^{x i i}$ is now demonstrating to be profoundly healthy."

- Daniel Levitin - Neurochemistry at McGill University

G3 relates music theory awareness with gifted. It is either you have it or you don't. G3 added that the "vocabulary" of music and songs is achievable through listening to music from all over the world. Other factors involvesknowledge on philosophy, psychology, religion and world.

G6 tells singers to instill the collective theories of perfection in vocal techniques like breathing, perfect intonation, appreciation and feeling of the song, tempo, articulation and improvisations.

\section{G3 $=4$ comments $\quad$ G6 $=1$ comment}

The results and findings obtained covers various aspects of singing and performance. Questions related to the aims and objectives revealed outcome that may be useful to new singers.

Feeling nervousprior to a performance is a worrying factor especially among new singers. Hence, from the findings we now know that breathing supplies oxygen to the lungs, body and mind thus helping ease and overcomingthefear and nervousness.

The findings also show that the most number of advice comes from G1 on Creativity (six comments); and Sincerity, Feel and Appreciation (six comments).

Collectively, the elements derived through Sincerity, Feel and Appreciationbags a total of eleven comments from the respondents. This proves that the prime factor in singing is to have sincerity, feel and appreciation.

Although that is primarily so, the other factors pertaining to singing that have been contributed by the respondents, must not be discarded or regarded as insignificant. All the findings are equally important and they are interdependent. They can be translated and defined as the pillar structures, and bridges of a building. If one is removed, the whole building will collapse. The synergies of all the factors must be embodied into one cohesive apparatus.

This study is now able to summarize the factors of singing into several important points:

- Establishing Signature Tone - Tone acquisition through resonance.

- Proper Breathing Techniques - Proper phrasing.

- Clarity - Diction and articulation.

- Embellishments - Creativity through vocal turns and acrobatics; dynamics and accents.

- Vocal Automation - Minimal Assist of auto - tune gadgets.

- Sincerity, Feel and appreciation is Supreme in Singing - The understanding of storytelling

\section{Conclusion}

A holistic comprehension of knowledge derived through this research shall be able to help a singer to perform better. The purpose of this journal is to uplift the standard of singing and music in Malaysia. Singing can be difficult and confusing if the singer does not understand the elements required to be able to deliver the art within the song. The advice given by the respondents along with the fundamentals provided in this study may be applied by singers. The technical aspects are cognitive elements that singers can heed to when performing or 
even prior to a performance. The non-cognitive elements involving feel and creativity may be tried out individually as different singers have different approach and background in life. These advice may be useful guides for new singers but the execution depends on the individual's gift and talent capabilities.

Further studies may be carried out by researchers on various other perspectives pertaining to singing and knowledge transfer. Other gifted singers can be selected as respondents to derive variety in opinions and experiences. Results from various digital platforms and having millenials $^{\text {xii }}$ and post-millenials ${ }^{x i v}$ as respondents may be alternatives to unravel future directions of Malaysian music.

\section{Acknowledgements}

The author would like to thank all the respondents for their sincere cooperation and comments. Sincere thanks also to AdzroolIdzwan and Ahmad Hisham for their engaging ideas and assistance rendered.

\section{References}

1. Daniel J. Levitin. 2008. The World in Six Songs: How the Musical Brain Created Human Nature. Dutton Penguin Books.

2. Daniel J. Levitin. 2006. This is Your Brain on Music: The Science of a Human Obsession. Dutton Penguin.

3. Frits Hesselink, 'Communicating nature conservations 10 frequently made mistake'.

4. Hans-Peter Blossfeld, Jutta Von Maurice. 14 (2), (19-34), 2011. Education as a lifelong process. ZeitschriftfürErziehungswissenschaft - link.springer.com

5. John Daniel Scott. 2010. https://nzcf.org.nz/wp-content/uploads/Scott-Singing-and-brain-function-1.pdf

6. Logan 2004 - Parveen, (2017).

7. Logan, B., Kositsky, A., \& Moreno, P. 2004. Semantic analysis of song lyrics. IEEE International Conference on Multimedia and Expo, 27-30 June 2004 Taipei, Taiwan.

8. Live Nation. 2017. How Malaysian Singer Yuna Became R\&B's Brightest New Star. https:/www.Intvglobal.com/id/article/how-malaysian-singer-yuna-became-rbs-brightest-new-star/.

9. MarienneUszler, Steward Gordon, Scott Mcbride Smith. 1999. The Well-Tempered Keyboard Teacher. Second edition. Schirmer.

10. Otto Jespersen. 1922. Language, Its Nature, Development and Origin.New York, Henry Holt and Co.

11. Paul Barker, Maria Huesca. 2004. 'Composing For Voice - Exploring Voice, Language and Music'

12. Rebekah Kaye Smeltzer. 2017. Body Weight, Nutrient, and the Classical Singer: A Review of the Existing Literature. https://scholarlyrepository.miami.edu/oa_dissertations/181 2017-04-21.

13. Richard Wagner and Rackham. 1876. The Ring of the Nibelung. https://www.goodreads.com/author/quotes/13890.Richard_Wagner.

14. Tan SooiBeng, Patricia Matusky. 1997. 'The Music of Malaysia: The Folk and Syncretic Traditions'.

\section{Notes}

${ }^{\mathrm{i}}$ A distinct emphasis given to a syllable or word in speech by stress or pitch

${ }^{\text {ii }}$ Vertical, horizontal, accent

${ }^{\text {iii }}$ Range from one music note to another

${ }^{\text {iv }}$ Pharynx and larynx

${ }^{\mathrm{v}}$ Indistinct sound running into one another

${ }^{\text {vi }}$ Displacing beat or accents of beats or accents in music/rhythm so that strong beats become weak and vice versa

${ }^{\text {vii }}$ A clef that puts the $\mathrm{G}$ above middle $\mathrm{C}$ on the second line of a staff (higher range notes)

viii A musical staff carrying the bass clef (lower range notes)

${ }^{\text {ix }}$ Original voice-tone

${ }^{x}$ Set of theories and therapeutic techniques related to the study of the unconscious mind

${ }^{x i}$ Many notes per syllable

xii The study of chemicals like neurotransmitters and other molecules that control the physiology of the nervous system

xiii Those born between the year 1983 to 2000

xiv Those born after the year 2000

\section{Biodata}


Mohd Azhar b Abu Bakar @ Azmeer is a currently a Fellow at the School of Creative Industry Management \& Performing Arts, Universiti Utara Malaysia, Kedah, Malaysia. His research focuses on the vocal study and performance analysis. He is also one of Malaysia's prolific multi-award winning composer and song producer. Email: ab.azmeer@yahoo.com

Dr Adzrool Idzwan Ismail is an Associate Professor and Manager of Creative Arts and Commercial Eventat the School of Creative Industry Management and Performing Arts; Universiti Utara Malaysia, Kedah, Malaysia. His area of specialization is Visual Communication, Photography and Creative Industry Management. Email: adzrool@uum.edu.my

Dr. Ahmad Hisham Zainal Abidin is currently the Dean at the School of Creative Industry Management and Performing Arts, Universiti Utara Malaysia, Kedah, Malaysia. He is in the Information Technology field and actively involved in script writing for TV content. Email: hishamza@uum.edu.my 